Man and Nature

L'homme et la nature

\title{
Hume's Tu Quoque: Newtonianism and the Rationality of the Causal Principle
}

\section{Michael Haynes}

Volume 7, 1988

URI : https://id.erudit.org/iderudit/1011930ar

DOI : https://doi.org/10.7202/1011930ar

Aller au sommaire du numéro

Éditeur(s)

Canadian Society for Eighteenth-Century Studies / Société canadienne d'étude du dix-huitième siècle

ISSN

0824-3298 (imprimé)

1927-8810 (numérique)

Découvrir la revue

Citer cet article

Haynes, M. (1988). Hume's Tu Quoque: Newtonianism and the Rationality of the Causal Principle. Man and Nature / L'homme et la nature, 7, 131-139.

https://doi.org/10.7202/1011930ar

Copyright (C Canadian Society for Eighteenth-Century Studies / Sociéte canadienne d'étude du dix-huitième siècle, 1988
Ce document est protégé par la loi sur le droit d'auteur. L'utilisation des services d'Érudit (y compris la reproduction) est assujettie à sa politique d'utilisation que vous pouvez consulter en ligne.

https://apropos.erudit.org/fr/usagers/politique-dutilisation/ 


\section{Hume's Tu Quoque: Newtonianism and the Rationality of the Causal Principle}

Rules I and II of Sir Isaac Newton's 'Rules of Reasoning in Philosophy' read, respectively, 'We are to admit no more causes of natural things than such as are both true and sufficient to explain their appearances,' and 'Therefore to the same natural effects we must, as far as possible, assign the same causes. ${ }^{1}$ In his Preface to the first edition of the Principia, Newton wrote that "the whole burden of philosophy [i.e., physical science] seems to consist in this - from the phenomena of motions to investigate the forces of nature, and then from these forces to demonstrate the other phenomena. ${ }^{2}$ And elsewhere, Newton reported that the causes of bodies' motions constituted the very reason for his writing the Principia to begin with. ${ }^{3}$

It has been argued that David Hume, some five decades later, set himself the task of accomplishing for the study of man what Newton had done for the heavens and the earth. ${ }^{4}$ Newton, recall, had unified the two domains. Hume sought to further unify them with the realm of the moral sciences. As John Passmore has noted: '[M]oral science [as far as Hume was concerned] had yet to experience its Newtonian revolution' and Hume himself proposed to be 'the Newton of the moral sciences. $^{5}$

Kant, too, found the same two domains - the heavens above and the moral realm within - to be of special interest to himself. And indeed, Newton's influence extended far beyond the relatively narrow confines of physical science, in a way unmatched by any other modern scientist with the possible exception of Charles Darwin. (For my part, I find the history of philosophy - and of theology - after the 17th century to be incomprehensible without some understanding of Newton.)

Yet, there is something especially puzzling about Hume's Treatise. If Hume was, indeed, inspired by the project of extending Newtonian attainments to the study of man, then was it not (to say the least!) more than a little curious that he virtually began his programme by 
undermining the rationality of a crucial principle employed by Newton (and others), viz., the causal principle, thereby, at least by implication, threatening to reduce it to the status of something very like a 'hypothesis' of the sort that Newton had himself sternly repudiated? (For Newton's views on 'hypotheses,' see, among other places, Bk. III of the Opticks.)

Hume's theory of 'natural belief' thoroughly devastated rationalism, and, as is well known, inspired Kant to turn Newtonianism into an a priori valid system: Newtonian principles, for Kant, literally defined the operations of the synthesizing mind! Thereby was rationality to be saved!

This latter development came, in time, to nought. That story is well known, however, and I shall not rehearse it here. Rather, my interest at this time is Hume's savaging of rationalism, in the context of an avowed search for a 'Newtonian' account of the moral sciences. Why on earth would Hume essay a defence and development of Newtonianism by destroying the grounds of one of its central operative principles - on which, after all, universal gravitation, and, indeed, if Newton was correct, the whole of 'philosophy,' depended?

One might reply that Hume's radical empiricism led him ineluctably to his irrationalist conclusions concerning causality (and other fundamental principles, e.g., substance and the self), and that he was just being honest about the whole thing. Perhaps; but I doubt that this is an adequate answer. As well, one might agree with Norman Kemp Smith when he argues that Hume's Newtonianism was occasionally offset by biological analogies, which he allegedly got from Hutcheson:

The processes of mind, as Hume recognizes, are adaptive, not mechanical in character, and in final outcome it is in the resources of human nature as exhibited in the instincts, passions and affections, not in the operation of association [the glue of the mind for Hume, as gravitation was the glue of the universe for Newton] that he finds the solution of his chief problems. ${ }^{6}$

This, too, though a pertinent remark, could be construed as inadequate to account for such a fundamentally radical move as Hume made vis-àvis the principle of necessary connection. After all, a biological account of the workings of the mind is not excluded by a mechanical causal account. Indeed, in the Treatise the two are firmly united: Hume gives us a mechanical (i.e., causal) account of (natural) belief, wherein psychology supplants epistemology and logic. (This, incidentally, includes a causal account of the [irrational] belief in causality!)

Another aspect of Hume's intentions should not go unnoticed here. Hume considered the Berkeleian claim that the primary qualities - a 
main focus of the new mechanical philosophy of nature forged in the 17 th century - actually reduce to secondary qualities, and that, consequently, 'material' objects are (in some sense) in the mind. This is a palpable threat to the mechanical world-view and to the special status accorded by it to primary qualities and causality (for Berkeley, only God can genuinely cause anything, which he does in our minds). The Humean doctrine of 'natural belief' could conceivably have been intended to overcome any scepticism regarding a mind-independent external world; and thus naturalism could have served to bolster the case against a doctrine that is, quite frankly, rationally irrefutable, viz., Berkeleian Idealism.

But if this were Hume's intention, it might well be viewed as a regrettable one. Consider: to appeal to naturalism in order to save materialism, and with it mechanism, is, it could well be argued, sadly ad hoc; for it would be tantamount to declaring, 'Your arguments are rationally undefeatable. Accordingly, I maintain that natural belief makes mincemeat of arguments and of their strange sceptical consequences, and repairs the damage done by them.' If, that is, one cannot vanquish an argument, then one simply declares all argument to be irrelevant or perverse. (As it happens, Hume's philosophical anthropology - like Kant's later - was universalistic: since everyone around the globe is fundamentally like everyone else, our natural beliefs - which serve utility - will mesh, and chaos will not ensue. Thus Hume, though an irrationalist, was very much an optimist.)

On the other hand, one might construe the application of naturalism against Berkeleian Idealism as an interesting unintended consequence of the case against Leibniz and company - and thus as constituting something of a weak but legitimate independent test of the Humean position. I do not know if this is indeed what happened with Hume; but it might be worth investigation.

I am inclined to think that, as legitimate and helpful as Passmore's and Kemp Smith's remarks may be - e.g., there is Passmore's useful reference to Hume's willingness to criticize Newton as regards space and time - there is is nonetheless more to the story that needs to be told. ${ }^{7}$ I suspect that Hume had something else in mind, which, so far as I know, he did not state explicitly, but which it would have been quite natural for him to have taken up at the time and easy enough for his contemporaries to have divined from his dicussion (scholars were more conversant, at that time, with their problem-situations than they are today). I shall state my conjecture in a moment; first, a few more preliminary remarks are in order.

One salient point that comes to mind as regards the role of causality in the Newtonian world-picture is the following. Newton believed in 
absolute time, absolute space and absolute motion. Now absolute motion is the translation of a body from one absolute space into another. ${ }^{8}$ In this connection, Newton's problem became that of distinguishing the different states of motion of bodies from one another. This cannot be done kinematically. The task, therefore, was to distinguish rest from motion dynamically, e.g., with reference to centrifugal force. As Newton wrote: "The causes by which true and relative motion are distinguished, one from the other, are the forces impressed upon bodies to generate motion. ${ }^{\prime 9}$

Now since the parts of immovable, absolute space are indistinguishable by the senses, it becomes difficult to distinguish true motion from apparent motion. Difficult, but not impossible. Newton rose to the challenge by suggesting the following experiment: connect two globes at a fixed distance by a cord, and revolve the two about their common centre of gravity. From the resulting tension in the cord, one could 'discover the endeavour of the globes to recede from the axis of their motion' and thereby measure 'the quantity of their circular motion. ${ }^{\prime 10}$

Thus causality played a crucial role in the Newtonian system; and, of course, Laplace turned the Newtonian universe into a closed, deterministic world, wherein an omniscient being, armed with knowledge of all the motions and configurations of the constituent corpuscles of the universe at any one time, and knowing Newton's laws of motion and of universal gravitation, could predict - as well as retro-dict - every state of events that ever did, or would, occur, thereby erecting causality (necessary connection, which permits pre- and post-diction to begin with) into a sine qua non of any rational science. As well, Laplace's correction of Newton's account of instabilities in the system of the world, somewhat ironically, drove one of the last nails into the coffin of the scientific defence of God's existence.

Newton, it should be pointed out, encountered numerous difficulties in working out the details of his world-system - difficulties which he never managed to resolve (which might be one reason why he declined to debate with his opponents publicly). Hume's disagreements with him could, admittedly, be ascribed in part to this fact. The most intractable, and notorious, of such difficulties was the status of universal gravitation. Another problem was Newton's vacillation concerning his claim that the fundamental constituent 'corpuscles' of the universe are indestructible and rigid: if so, the second law of motion, $\mathrm{F}=\mathrm{ma}$, encounters the problem of instant acceleration upon collision of rigid bodies, and, with that, the operation of infinite force. A third problem comprised the status of inertia: at times, Newton described inertia as an 'innate' force which continuously acts so as to conserve bodies in their states of rest or straight-line motion; whilst, at other 
times, he construed inertia as an inherent 'power' of resistance to change of state which is brought into operation when a body is acted upon by external forces (the latter is natural if the third law of motion is correct). ${ }^{11}$

Yet, the explanation of apparent disparities between Hume and Newton in terms of Newtonian confusions or uncertainties could be viewed as weaker than might be desired. In any case, it will not suffer from being supplemented. Before presentation of my own thesis about Hume, however, one more brief detour is in order.

I am referring now to Newton's debate with Leibniz (via the Reverend Samuel Clarke, Newton's spokesman). One central theme of that celebrated exchange was the status of Newtonian universal gravitation. Leibniz protested against Newtonian 'action at a distance' that

A body is never moved naturally, except by another body which touches it and pushes it; after that it continues until it is prevented by another body which touches it. Any other kind of operation on bodies is either miraculous or imaginary. ${ }^{12}$

Elsewhere, Leibniz elaborated his theory of action by contact as follows:

[A]n attraction, properly so called, or in the scholastic sense, would be an operation at a distance, without any means intervening ... [A]n attraction without any means intervening, would be indeed a contradiction ... [W] hat does [Mr. Clarke] mean, when he will have the sun to attract the globe of the earth through an empty space? Is it God himself that performs it? But this would be a miracle, if ever there was any ... That means of communication (says he) is invisible, intangible, not mechanical. He might as well have added, inexplicable, unintelligible, precarious, groundless, and unexampled ... 'Tis a chimerical thing, a scholastic occult quality. ${ }^{13}$

Leibniz's view was Cartesian: it repudiated action at a distance as nonmechanical, and opposed to it mechanics as a philosophy of motion as caused by push - by contact, collision. ${ }^{14}$ (Though Leibniz, who thought of himself as anti-Cartesian, corrected Descartes by repealing the principle of conservation of motion and replacing it with something like vectorized conservation of momentum - it was actually closer to $\mathrm{ki}$ netic energy [which Huygens also formulated] - as well as, like Newton, rejecting Descartes's equation of matter with space and consequent virtual reduction of physics to geometry. $)^{15}$

Action between non-contiguous bodies, then, had, for Leibniz, to be communicated by way of an intervening medium. (The discussion 
of causality in terms of contiguity, a term employed, of course, by Hume as well, is Cartesian - as well as Hobbesian.) ${ }^{16}$ And it is this theme in the history of ideas that I want to stress with my thesis about Hume. It is high time that I present it.

My conjecture is this. Hume's sustained assault on the rationality of the causal principle was intended, in at least appreciable part, as a tu quoque directed at the Leibnizians (who were, in the most relevant sense, Cartesians), who were forging what eventually got translated into field-theory (a theory of action in the neighborhood, or in the vicinity) and were Newton's severest critics. In effect, Hume was proclaiming: 'You object that action at a distance is occult. You propose, in its stead, action by contact. But - by your own standards! - you, too (tu quo$q u e)$, must be irrationalist; for the causal principle, on which your mechanics rest, is itself irrational! You, too, are dabbling in occultism!'

In connection with all this, let me draw attention to paragraph 124 of Leibniz's fifth paper:

All the natural forces of bodies, are subject to mechanical laws; and all the natural powers of spirits, are subject to moral laws. The former follow the order of efficient causes and the latter follow the order of final causes. [Italics mine] ${ }^{17}$

Hume, to reiterate, composed his Treatise as a 'Newtonian' account of the moral sciences - i.e., of the study of what Leibniz here terms 'spirits.' Therein lies another possible direct connection between Leibniz and Hume. This consideration could, theoretically, lend extra weight to my conjecture that a good part of Hume's intentions was that of making a salient point to the Leibnizian natural - and moral - philosophers: viz., that the irrationality of the causal principle is, in effect, a great 'equalizer.' Newton had, in the Principia, shown the inadequacy of the Cartesian fluid theory of the universe, of attraction (the latter Descartes had explained away). He repeated his attack in Query 22 of the Opticks. Huygens had appreciated the failure of the vortex-theory to explain the elliptical orbits of the planets. Leibniz, however, dismissed all objections: 'the gravity of sensible bodies towards the centre of the earth, ought to be produced by the motion of some fluid'; and he maintained that the difficulties of the vortex-theory could be overcome. ${ }^{18}$ Yet he failed to specify how; and thus his assurances were merely bare assertions.

Newton's argument, then, amounted to the following: the Cartesian hydrodynamics and hydrostatics fail. (Descartes had maintained that light is a pressure, in the aethereal fluid, that is instantaneously propagated in a single direction. Newton's hydrostatics refuted this.) Universal gravitation, in its mathematical form, describes the orbit of 
the moon about the earth and the motions of the planets (as well as the motions of the comets, as Halley so dramatically showed). Yet, Newton himself agonized over the ultimate explanation of action at a distance, which he generally found no more congenial than did his opponents. ${ }^{19}$ In response to this, and with his refutation of Cartesian fluid mechanics in mind, he decided not to worry about such ultimate causes - 'Hypotheses non fingo' - and to accept instead that, despite this explanatory lacuna, the theory of universal gravitation should be warmly received: it had undeniable merits, despite the problem of its ultimate explanation. ${ }^{20}$

Hume, then, may have viewed his philosophical task as that of strengthening the Newtonian account even more than had Newton himself with his critique - all-pervasive in the Principia - of Cartesian fluid-mechanics. This Hume could do by knocking the philosophical props out from under the opposition - in the form of the causal principle, on which the anti-Newtonian approach relied perhaps even more directly than had Newton's own account of things. The rationality of the causal principle now became everyone's problem - and thus non-discriminating as between Newton and the opposition. ${ }^{21}$ This would strengthen Newton's fluid-mechanical refutation of Descartes by taking out some of the sting of the Cartesian mechanical philosophy, viz., that pertaining to 'occult qualities,' thereby eliminating one of the attack-fronts. This would, in turn, put that problem on the same footing with the problem of (say) the perihelion of Mercury - which no one could satisfactorily solve until Einstein, later, and which thus did not threaten to undermine Newtonianism, though it did set an important agenda.

MICHAEL HAYNES

York University

\section{Notes}

1 Sir Isaac Newton, Principia, ed. by Florian Cajori (University of California, 1966), in 2 volumes. For Rules I and II, see vol. II, p. 398.

2 Principia, XVII - XVIII.

3 Principia, p. 12. 
4 In his A Treatise of Human Nature, 1739.

5 This is one of the themes of John Passmore's Hume's Intentions (Cambridge, 1952).

6 Norman Kemp Smith, The Philosophy of David Hume (London: MacMillan, 1941), p. 76. See, as well, pp. 549 f. of Kemp Smith, 'Concluding Comments.'

7 As it turns out, Hume was in France in 1725, at La Flêche, which was a hotbed of Cartesianism.

8 Principia, p. 7.

9 Ibid., p. 20.

10 Ibid., p. 23. Curvilinear motion was for Newton a guarantee of the operation of a net force, since it represented a continuous deflection from a natural state, viz., rest or rectilinear motion. This Huygens also realized. Berkeley attacked the mathematical description of such continuous deflection, viz., the method of fluxions (the calculus), and, with it, matter, since, as Newton had claimed to demonstrate, matter behaves according to those mathematics.

11 Yet, one might, alternatively, describe inertia as but a tendency to resist change of state on the part of matter, without invoking powers, forces or any other such agencies. Indeed, Newton himself wrote (Principia, p. 612): 'it is none of our present business to explain the causes of the appearances of Nature.' Hume's talk of 'constant conjunction' was possibly associated with just such considerations.

12 H.G. Alexander, ed., The Leibniz-Clarke Correspondence (Manchester: Manchester University Press, 1956), p. 66. There is an interesting complication regarding push and its scientific role. Descartes maintained that motion is due to push - this was modern mechanics as Descartes introduced it. Hobbes bought Cartesian mechanicism and extended it to morals and politics. Newton added pull to the phenomena of matter - not the pull of hooked matter, which occurs in Descartes, but the troublesome gravitational attraction operating between masses immediately they come into existence, which Cartesians regarded as 'occult,' and hence irrational. Electrical and magnetic attraction, too, were not regarded by Newton as reducible to mechanical push. But something more interesting - a bit of a twist - occurs in the story. It is this: Descartes regarded push as a fundamental explanatory principle: it was the basis of his mechanical philosophy. Yet, Bernouilli's principle suggests that this allegedly fundamental principle itself stands in need of explanation - in terms of pressure. One's fundamental explanations are always subject to further, more fundamental, explanations.

13 Alexander, p. 94.

14 Huygens considered himself a non-Cartesian, yet he was more Cartesian than was Newton. For instance, he interpreted centripetal force vortically. Though he modified Descartes' vortices, this still kept him in the Cartesian camp relative to Newton's repudiation of any Cartesian-type vortices. As well, Huygens held that explanations should be ultimate - i.e., that one should arrive at hypotheses that get behind appearances, which is an aim that Newton (generally) decried. On this, Huygens agreed with Descartes. Leibniz, on the other hand, regarded himself as anti-Cartesian. He accepted that matter is extension, but added impenetrability, in terms of repulsive forces. Descartes had failed to 
explain impenetrability and had rejected forces. On the other hand, Newton himself was a Cartesian, in certain respects anyway (perhaps as Jung remained a Freudian?). So: who was, and who was not, a 'Cartesian'? This is something of a problem for the philosophy of 'research programmes,' whereby one seeks descriptions of, and recommendations for, scientific research in terms of 'hard cores' or dominant metaphysical hypotheses. For criticism of this general approach, see my 'Problems versus Programmes in Science and the Philosophy of Science,' Philosophia, Vol. 15, No. 3, December 1985.

15 Descartes is frequently regarded as having equated physics and geometry - or reducing one to the other. But E.A. Burtt suggests that this was not the case. (It was certainly problematical.) See his The Metaphysical Foundations of Modern Physical Science (London: Routledge and Kegan Paul, 1924), p. 99.

16 Thomas Hobbes, Elements of Philosophy, Bk. II, Ch. 9, Par. 7, and Bk. IV, Ch. 26, Par. 8, 7 .

17 The Leibniz-Clarke Correspondence, p. 85.

18 Ibid., p. 66.

19 Indeed, Newton was at great pains to deny that gravity is essential to, i.e., inherent in, matter - which would obviate any intervening medium, and thus save Newton some aggravation, but which would also be regarded as 'occult.' (Cf. his third letter to Bentley, quoted in Burtt, p. 265. One gets the impression that with friends like Bentley and Cotes, Newton didn't need enemies!) Yet Newton never could satisfactorily explain gravity in terms of the aether, whose existence he relied on for a number of explanatory tasks. For instance, ironically enough, Newton appreciated the periodic properties of light, and invoked the aether to account for them; whilst Huygens, whose wave-view eventually 'won' the day, regarded light as an irregular wave-phenomenon. See A.I. Sabra, Theories of Light from Descartes to Newton (London: Oidbourne, 1967).

20 As noted, Descartes and Huygens agreed, against Newton, that science should seek ultimate explanations through fundamental hypotheses.

21 For the theory of 'discriminatory problems' and their place in science, see J.N. Hattiangadi, 'A Methodology Without Methodological Rules,' in Language, Logic and Method, ed. by R. Cohen and M. Wartofsky (Boston Studies in the Philosophy of Science: Reidel, 1983); and 'The Logic of Problems in the Empirical Sciences,' in Proceedings of the Vth International Congress in Logic, Methodology and the Philosophy of Science (London, 1975). 